\title{
Heat-efficient ceramic products based on modified rice straw
}

\author{
Mukhamad-Basir Kodzoev ${ }^{1 *}$, Sergey Isachenko ${ }^{1}$, Olimjon Rasulov ${ }^{2}$ and Maria Kaddo ${ }^{1}$ \\ ${ }^{1}$ Moscow State University of Civil Engineering, Yaroslavskoe shosse, 26, Moscow, 129337, Russia \\ ${ }^{2}$ Tajik Technical University named after academic M.S.Osimi, academics Radzhabovy str., 10, \\ Dushanbe, 734042, Tajikistan
}

\begin{abstract}
The current state of the building ceramics production is based on the following facts. Firstly, as a result of market conditions, the number of operating ceramics factories has significantly decreased. Secondly, considering the increase in the house construction rate due to the shift to new financing mechanisms, there has been an increase in the ceramic brick production by $2-3 \%$ since 2019 . Growth opportunities are associated with higher thermal efficiency of ceramic products and masonry based thereon. The research objective in this article was the development of compositions for wall heat-efficient ceramics based on loess low-grade loams with the use of rice straw as a burnout additive and, in particular, the determination of the optimal processed rice straw consumption. The scientific novelty of the research consisted in the development of a method for selecting the ceramic mixtures composition, optimizing the composition and substantiating the rice straw and rice straw ash influence on the ceramic mixtures and products properties.

Rice straw is introduced into clay masses at the preparation stage in an amount of $5-15 \%$ (by mass) of fluff rice straw, which burns out with burning temperature of $200-300^{\circ} \mathrm{C}$ and makes the mass porous, preventing shrinkage and forming ash containing up to $20 \%$ of amorphous silica. Carbonates in clay dissociate during firing, interacting with amorphous silica and forming various calcium silicates that strengthen the shard structure.
\end{abstract}

\section{Introduction}

The expansion of the wall ceramic products range and an increase in production thereof are the result of raising the bar for enclosing structures in terms of architectural expressiveness, thermal and performance properties [1-3]. It is also necessary to take into account the state of production, market characteristics and the supply and demand ratio, typical for this segment of the construction industry. These characteristics include the conversion to loams and other clays which were previously considered to be of limited use for ceramic production, and decline in demand for ceramic brick, resulting from the increased use of thermal insulation systems: ventilated facades or plaster facades [4-6].

\footnotetext{
*Corresponding author: basir731@yandex.ru
} 
The current state of the building ceramics production is based on the following facts. Firstly, as a result of market conditions and the promotion of multi-component facades and walls insulation systems, the number of operating ceramics factories has significantly decreased from 557 to 310 . Secondly, considering the increase in the house construction rate due to the shift to new financing mechanisms, the implementation of preferential mortgage programs and programs to support the construction complex under pandemic conditions, there has been an increase in the production of ceramic brick by $2-3 \%$. Growth opportunities are associated with higher thermal efficiency of ceramic products and masonry based thereon.

The state of the construction segment makes it necessary to search for new solutions that would allow to obtain competitive and heat-efficient types of products, while keeping the ceramic products appealing as such (possessing high durability, fire safety, strength, decorativeness, etc.) [7-9].

A possible direction for expanding the raw material base of wall ceramics is the use of siliceous opokalike rocks. Useful properties of loamy zeolite-containing raw material and its manufacturability are determined by the phase composition, crystal chemistry and structural features of its constituent minerals. The use of zeolite-containing clays or lowgrade clays with the addition of zeolite-containing components has a fluxing effect on clay masses, improves sinterability and mechanical strength of products [7-9].

One of the ways to reduce the thermal conductivity of ceramic products and increase the thermal resistance of masonry based thereon is the formation of a ceramic shard with a porous structure. Such structure can be obtained by introducing very light aggregates that are sintered in the ceramic shard mass a during ceramics firing, using the foam method or the burnout additives method [10-13].

Various burnout additives are used in the composition of ceramic masses: coal dust, saw-dust, expanded polystyrene dust, but the use of rice straw is of particular interest. Analyzing the methods of disposal of rice production waste, we can conveniently subdivide them into two categories: destruction, due to the above reasons; rational use with or without preliminary processing and preparation (Fig. 1).

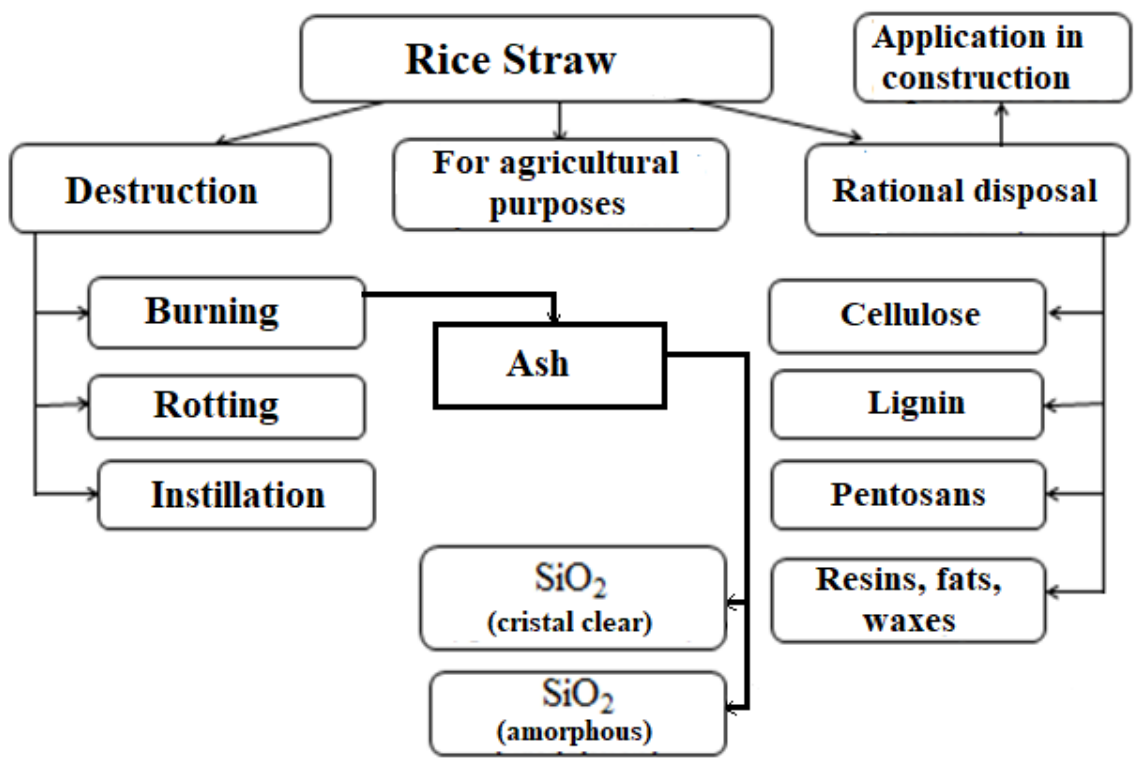

Fig. 1. Ways of the disposal of rice straw

Rice straw is introduced into clay masses at the preparation stage in an amount of 5$15 \%$ (by mass) of fluff rice straw, which burns out with burning temperature of $200-300^{\circ} \mathrm{C}$ 
and makes the mass porous, preventing shrinkage and forming ash containing up to $20 \%$ of amorphous silica. Carbonates in clay dissociate during firing, interacting with amorphous silica and forming various calcium silicates that strengthen the shard structure.

The research objective described in the article was the development of compositions for wall ceramics based on loess low-grade loams with the use of rice straw as a burnout additive and, in particular, the determination of the optimal processed rice straw consumption.

\section{Methods}

The loams used in the experiment belong to the group of coarse dispersed loamy raw materials by the content of the finely dispersed fraction (less than $0.001 \mathrm{~mm}-10.9$ $11.8 \%$ ). By the plasticity index (average value is 8 ), they belong to moderate plasticity and low plasticity clays. By the alumina content (A12O3 less than 16\%) referred to the ignition basis, they belong to the group of acidic loamy raw materials. By the content of iron oxides ( $\mathrm{Fe} 2 \mathrm{O} 3$ more than 3\%), they belong to the group of materials high in coloring oxides. The average clay moisture is $1.96 \%$, the average density is $1.47 \mathrm{t} / \mathrm{m} 3$, the fragmentation index is 1.14 .

Rice straw is a fine-fiber material, ready for insertion into a clay composition, with the following technical characteristics: bulk density is $180-200 \mathrm{~kg} / \mathrm{m} 3$; average fiber diameter is $50-100 \mu \mathrm{m}$; average fiber length is $1-2 \mathrm{~mm}$; flowability is $45^{\circ}$; fire point is $200-220^{\circ} \mathrm{C}$.

The screw system is most widely used in plastic molding at ceramic brick factories, since it allows to ensure the continuity of the process, and at the same time work is done in a vacuum and a better paste homogenization is achieved. Under laboratory conditions, with limited use of raw materials, the most acceptable device is a device operating on the principle of a piston extruder (Fig. 2).

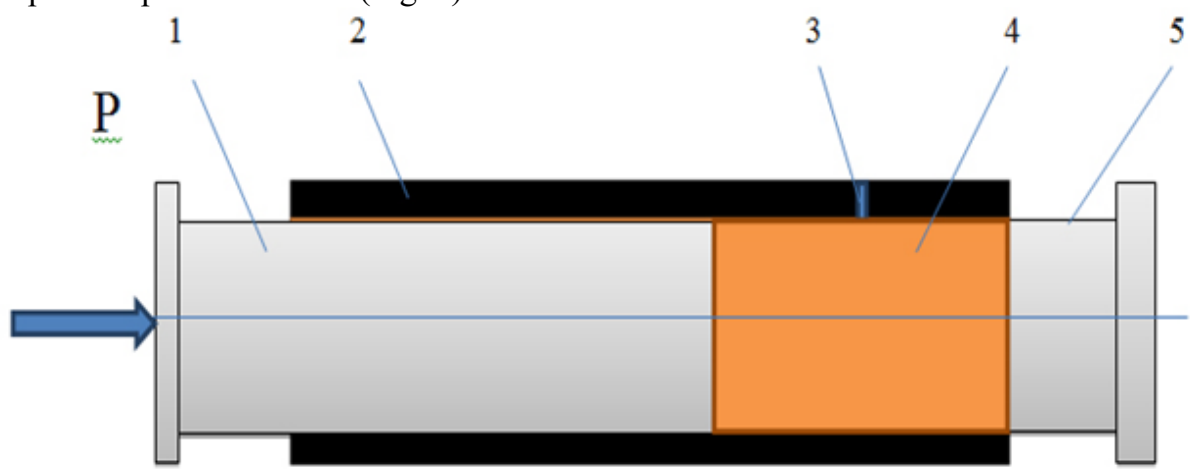

Fig. 2. Scheme of a piston extruder type device for samples molding: 1 - piston; 2 - rectangu-larsectioned casing; 3 - hole; 4 - clay mass; 5 - stopper

Procedure for samples molding is as follows: clay mass (4) with the required molding moisture and calculated volume is placed inside a rectangular-sectioned metal casing (2) moistened with machine oil; the stopper (5) is installed; under the influence of the piston (1), the clay mass is moved to the stopper; it is squeezed until an excess of mass appears in the control hole (3) of the casing; the stopper is removed and the molded sample is squeezed out of the casing.

Experiments on the selection of the ceramic mixtures composition using rice straw as a burnout additive and rice straw ash as an active mineral component were carried out based on the methods of mathematical planning and processing of experimental results $[14,15]$, and the analysis of equations and determination of optimal costs were carried out based on analytical optimization method [16, 17]. 


\section{Experimental \& Results}

The plot shows that with the addition of rice straw $(3,6,9$ and $12 \%)$ to the formulation of the clay composition, the density of the fired samples decreases, respectively, from $1.71 \mathrm{~g} / \mathrm{cm} 3$ to $1.38 \mathrm{~g} / \mathrm{cm} 3$ and to $0.95 \mathrm{~g} / \mathrm{cm} 3$. At the same time, the porosity increases, respectively, from 33 to 45 and further to $60 \%$, while the thermal conductivity decreases and the efficiency of the enclosing structure increases.

The state standard SNiP 23-02-2003 Thermal protection of buildings provides, with the above test results for density and porosity and taking into account the humidity of the environment of products use, indicators for thermal conductivity, respectively, of the order of $0.6 ; 0.4$ and $0.2 \mathrm{~W} / \mathrm{m} \cdot{ }^{\circ} \mathrm{C}$.

Studies of the effect of adding rice straw to a clay composition on the change in its thermal conductivity were carried out at ISA MGSU by measuring the rate of temperature change when heating a cylindrical probe immersed in a sample of a material of a certain shape, in accordance with GOST 30256-94

The research results showed that when up to $10 \%$ of fluff straw is introduced into the clay, the density of fired samples decreases from 1.7 to $1.1 \mathrm{~g} / \mathrm{cm} 3$, and the thermal conductivity coefficient decreases from 0.6 to $0.27 \mathrm{~W} / \mathrm{m} \cdot{ }^{\circ} \mathrm{C}$. This means that the product, in terms of thermal conductivity, goes from the class of ineffective wall materials to the class of effective ones.

Having carried out a comparative analysis of the use of the influence of the rice straw addition on the clay or loam properties, we came to the conclusion that the addition of straw in an amount of $5-15 \%$ by mass sharply reduces the density of a ceramic shard with a significant loss of compressive strength (see Tables 1 and 2).

Table 1. Comparative characteristics of clay compositions with the addition of rice straw

\begin{tabular}{|c|c|c|c|}
\hline Description of clay & $\begin{array}{c}\text { Average density, } \\
\mathbf{~ k g / m 3}\end{array}$ & $\begin{array}{c}\text { Compressive } \\
\text { strength, MPa }\end{array}$ & $\begin{array}{c}\text { Water } \\
\text { absorption, } \%\end{array}$ \\
\hline Clay+ Straw (5\%) & 1580 & 11.1 & 17.3 \\
\hline Clay+ Straw (10\%) & 1290 & 5.0 & 22.5 \\
\hline Clay+ Straw (15\%) & 1010 & 1.6 & 30.4 \\
\hline
\end{tabular}

Table 2. Comparative characteristics of clay compositions with the addition of rice straw or ash

\begin{tabular}{|c|c|c|c|}
\hline Description of clay & $\begin{array}{c}\text { Average density, } \\
\text { kg/m3 }\end{array}$ & $\begin{array}{c}\text { Compressive } \\
\text { strength, MPa }\end{array}$ & $\begin{array}{c}\text { Water } \\
\text { absorption, \% }\end{array}$ \\
\hline Clay+ Straw/Ash (5\%) & $1272 / 1326$ & $7.26 / 6.3$ & $26.91 / 28.7$ \\
\hline Clay+ Straw/Ash (10\%) & $1086 / 1286$ & $2.25 / 5.7$ & $33.24 / 27.5$ \\
\hline Clay+ Straw/Ash (15\%) & $882 / 1200$ & $0.63 / 2.7$ & $41.37 / 32.0$ \\
\hline
\end{tabular}

\section{Discussion}

Rice straw in the form of a fine-fibred loose mass and ash, formed as a result of burning straw, in the form of a highly dispersed granular mass have different effects on the processes of forming, drying and firing of samples, as well as the properties of raw, adobe and shard.

Straw is a non-woody plant matter and when the raw material is heated, as early as $350^{\circ} \mathrm{C}$, it begins to smolder intensively to about $500-550^{\circ} \mathrm{C}$, emitting combustion products in the form of flue gases and decomposing, turns into ash. In this process, a reducing agent is formed in the sample, which affects the firing process and the formation of a shard. 
Thus, straw is actually a burnout additive, but it differs from the classic burnout additives, both in the form of wood waste and waste from coal production. This difference lies in the fact that burning rice straw forms amorphous silica, which under certain conditions is able to interact with the products of clay sintering.

Ash obtained by burning straw under conditions of brick production in a thermal unit in an oxidizing environment is $89-91 \%$ silica and $11-9 \%$ oxides of potassium, sodium, calcium, magnesium and iron. Moreover, the form of silica is mostly crystalline. Thus, ash is actually an inert thinning additive and its effect on raw material and ceramic shard is somewhat different from that of straw.

Considering the fact that straw is a more active component than ash in the studied compositions, the following ratios of clay and additive are accepted: in the clay - straw composition (straw consumption from 3 to $12 \%$ by mass), in the clay - ash composition (ash consumption from 5 to $12 \%$ by mass).

The study investigated the influence of the content of rice straw and ash (separately) on molding moisture content, raw material density, drying shrinkage, density and strength of the shard, as well as water absorption, thermal conductivity and frost resistance (saturation coefficient).

With an increase in the content of additives from 3 to $15 \%$ by mass of clay, the molding moisture content of the clay composition increases significantly from 20 to $32 \%$ in the case of ash addition and up to $41 \%$ for straw. This high increase in molding moisture content is due to the structural feature of the additives. Thinning additives generally reduce the molding moisture content of the clay composition. Ash, on the contrary, increases moisture content due to its high dispersion approaching the dispersion of clay. The straw further increases the molding moisture content due to its fine fiber structure and high water retention capacity.

It should be noted that with an increase in the molding moisture content of the clay composition, the density of the samples sharply decreases after drying already, and the porosity increases, while shrinkage is practically unchanged. When the samples are heated, in the first firing phase, the porosity of the samples with the addition of straw increases even more due to the emission of gaseous products of straw combustion, the volume of which reaches $80 \%$.

As shown above, the density of the samples sharply decreases when straw or ash is added to the clay composition. When $5 \%$ straw is introduced into the clay, the density of the composition decreases from $1575 \mathrm{~kg} / \mathrm{m} 3$ to $1275 \mathrm{~kg} / \mathrm{m} 3$, i.e. by $19 \%$; with the introduction of $10 \%$ straw, the density decreases to $1085 \mathrm{~kg} / \mathrm{m} 3$, i.e. by another $15 \%$, and with $15 \%$ of the additive, the density decreases to $880 \mathrm{~kg} / \mathrm{m} 3$. When ash is added to the clay, the density decreases more smoothly, and with the $15 \%$ content, reaches only 1100 $\mathrm{kg} / \mathrm{m}^{3}$.

Obviously, with a decrease in the density of samples, their strength should also decrease in proportion. However, the loss of density in samples with the addition of ash is much greater than in ones with straw. This is the evidence of the fact that amorphous straw silica interacts with the components of the forming shard, and is not inert. 


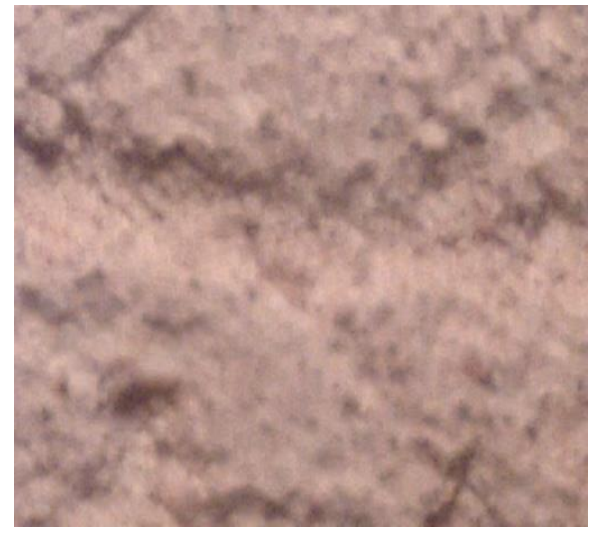

$\boldsymbol{a}$

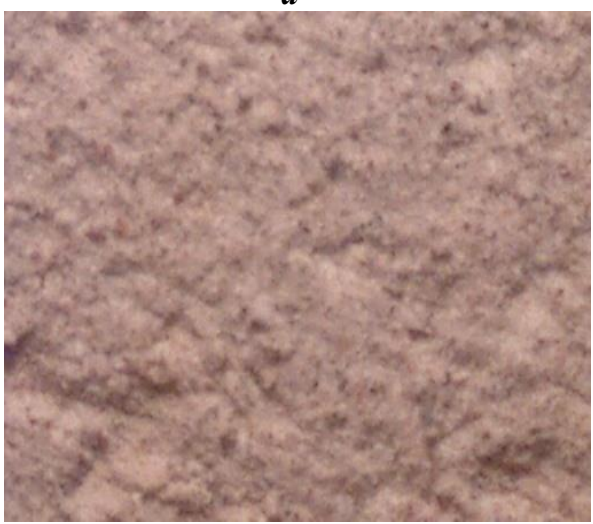

$c$

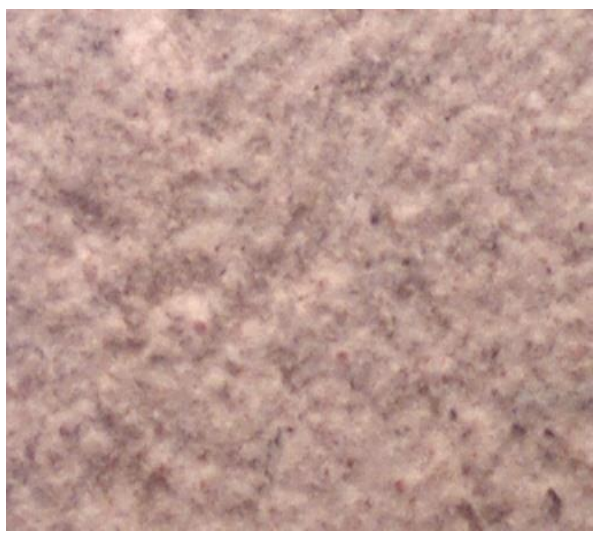

b

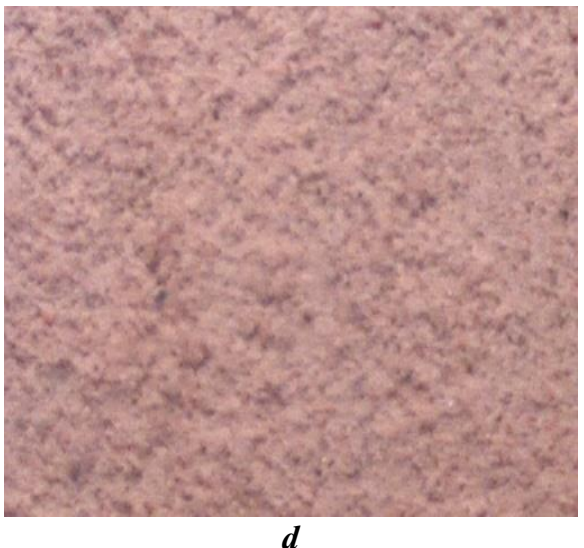

Fig. 3. Macrostructure of a shard of the composition of clay and ash of rice straw at 60 times magnification: a - clay $85 \%$, ash $15 \%$; b - clay $90 \%$, ash $10 \%$; c - clay $95 \%$; ash $5 \%$

Index of water absorption of a shard is an indirect characteristic of its structure (Fig. 3). In addition to density and strength indexes, water absorption significantly affects the operational properties of the shard, specifically, water resistance and frost resistance. The nature of the shard porosity affects its thermal conductivity.

A decrease in the shard density, both with the addition of straw and ash, approximately equally increases its water absorption. High water absorption in the samples under study is associated with the fine-pored structure of the obtained samples, and water resistance and frost resistance of products depend mainly on the strength of the structure. The thermal conductivity index of wall ceramic products is significantly related to the size and nature of the pores of their structure. 


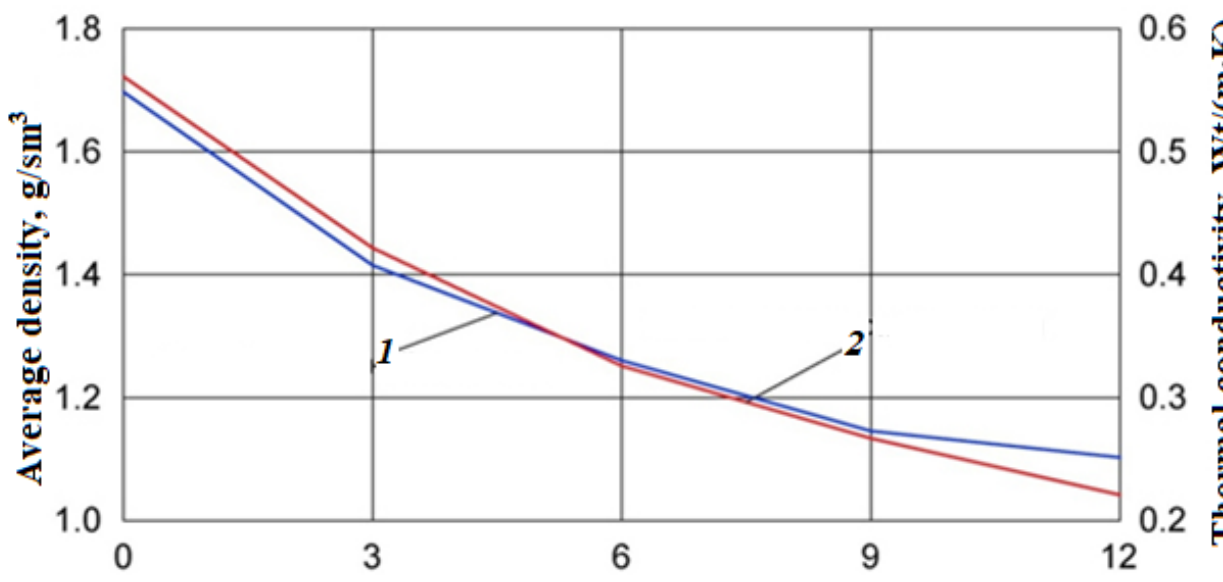

The content of the burnout additive, $\%$

Fig. 4. Influence of the content of rice straw in the composition of clay masses on the density and thermal conductivity of wall ceramic products: 1 - average density; 2 - thermal conductivity

\section{Discussion}

The use of rice straw as a burnout additive and rice straw ash as a thinning additive in the bricks production makes it possible to obtain ceramic products that meet modern requirements for wall enclosing structures. As a result of firing samples of loess loam with the addition of rice straw and rice straw ash, a stable ceramic shard is formed during sintering, consisting of quartz and feldspars in the presence of new formations of calcium aluminosilicates and magnesilicates. The use of rice straw as a technological additive in the bricks production creates a reducing agent during the firing process and contributes to a more complete sintering of the shard.

Optimal technological parameters are the following: degree of fineness (fluffing) of straw, molding moisture content and plastic strength of the dough, drying and firing mode. The molding moisture content of the clay mixture varies from 20.0 to $24.5 \%$ depending on the straw content. When using an additive in the form of ash, a plastic molding method was also used with a molding moisture content of $18.5-23.5 \%$ at a pressure of $1.2-1.4 \mathrm{MPa}$ in the extruder. Firing temperature is $900-1000^{\circ} \mathrm{C}$. With an increase in straw content up to $15 \%$, the average density of a ceramic shard decreases to $900 \mathrm{~kg} / \mathrm{m} 3$

The use of loess carbonate-containing clays with additions of $6-9 \%$ rice straw and 12 $18 \%$ rice straw ash as raw materials to obtain wall ceramics of low density and, subsequently, high thermal resistance, makes it possible to significantly expand the raw material base and utilize huge waste from rice processing.

\section{References}

1. A. A. Semenov, The state of the Russian market of ceramic wall materials, Building materials. 8. - P. 9-12 (2014).

2. M-B. Kodzoev, S. Isachenko, E. Bobrova, B. Efimov and I. Bessonov, Ceramic products and energy-efficient systems 032006, XXIII International Scientific Conference on Advance in Civil Engineering: "CONSTRUCTION - THE FORMATION OF LIVING ENVIRONMENT" (FORM-2020) 23-26 September 2020, 
Hanoi, Vietnam. Accepted papers received: 20 May 2020 Published online: 09 July Volume 869 doi:10.1088/1757-899X/869/3/032006 (2020).

3. P.M. Zhuk, A.D. Zhukov, Regulatory legal framework for environmental assessment of construction materials: prospects for improvement // Ecology and Industry of Russia. No. 4. - pp. 52-57 (2018).

4. O. I. Lobov, A. I. Anan'ev, A. A. Anan'ev, Energy efficiency, durability and safety of exterior walls of buildings made of ceramic materials. Stroitel'nye materialy -2010. No. 4. - p. 10-15 (2010).

5. M.K. Ischuk, O.K. Gogua, I.G. Frolova, Features of the work of flexible connections in walls with a face layer of masonry. Stroitel'nye materialy, 2013, no. 2018. № 7. - pp. 40-44 (2018).

6. O. I. Rubtsov, E. Yu. Bobrova, A.D. Zhukov, E. A. Zinovieva, Ceramic bricks, stones and full-brick walls / / Stroitel'nye materialy. 2019. No. 9. pp. 8-13 (2019).

DOI: https://doi.org/10.31659/0585-430X-2019-774-9-8-13.

7. B. V. Talpa, V. D. Kotlyar, Yu. V. Terekhin, Rating opoka-like siliceous rocks for the production of ceramic bricks / Talpa B. V., V. D. Kotlyar, V. Terekhina // Stroitel'nye materialy. - 2010. - No. 2. - pp. 8-10 (2010).

8. B.V. Tolpa, V.D. Kotlyar, Siliceous clay is perspective raw materials effective wall ceramic / B.V. Tolpa, V.D. Kotlyar - Proceedings the second In the national conference «Clays minerals and layered materials 2013»-CMLM, 2013, P. 107 (2013).

9. G. I. Gorbunov, O. R. Rasulov, Problems of rational utilization of rice straw. // Vestnik MGSU. - 2013. - No. 7. - pp. 106-113 (2013).

10. G. A. Ashmarin, N. And. Naumkin, A. M. Gubaidullin, V. G. Swallow, Ceramic wall materials based on zeolite-containing clay raw materials / A. G. Ashmarin, N. I. Naumkina, A.M. Gubaidullina, V. G. Lastochkin / / Stroitel'nye materialy. - 2010. - No. 4. - p. 44-46 (2010).

11. N. G. Gurov, The choice of effective technologies in the production of wall ceramic products in modern conditions / N. G. Gurov / / Stroitel'nye materialy. - 2004. - No. 2. pp. 6-7 (2004).

12. G. I. Gorbunov, O. R. Rasulov, The use of rice straw in the production of ceramic bricks. // Vestnik MGSU. - 2014. - No. 11. - pp. 128-136 (2014).

13. G. I. Gorbunov, O. R. Rasulov, On the issue of improving the efficiency of building ceramic materials. // PGS. - 2015. - No. 8. - p. 19-2114. Rumyantsev B.M., Perfilov V.A., Pilipenko A.S., Kosukhin M.M., Pyataev E.R. Mechanical impacts and operational reliability // Innovations in life 2016. №4 (19). - pp. 7-15 (2016).

14. A.D. Zhukov, M.O. Asamaddinov, A.S. Chkunin, K. K. Ivanov, G. B. Rumyantsev. Wall materials based on local raw materials // Innovations in life 2016. №4 (19). -ppp. 35-43 (2016).

15. A. D. Zhukov, E. Y. Bobrova, I. V. Bessonov, A. A. Medvedev, B. A. Demissi, Application of statistical methods for solving problems of construction materials science / / Nanotechnologies in construction. - 2020. - Volume 12, No. 6. - pp. 313-319. -DOI: 10.15828/2075-8545-2020-12-6-313-319 (2020).

16.A. Zhukov, E. Shokodko, Mathematical Methods for Optimizing the Technologies of Building Materials In: Z. Popovic, A. Manakov, V. Breskich. (eds) VIII International Scientific Siberian Transport Forum. TransSiberia 2019. Advances in Intelligent Systems and Computing, vol 1116. Pp. 413-421. Springer, Cham. First Online 31 January 2020. -DOI: https://doi.org/10.1007/978-3-030-37919-3_40. Print ISBN978-3030-37918-6. Online ISBN978-3-030-37919-3 